\title{
Genetic Diversity Assessment in Chickpea (Cicer arietinum L.) through Agro-morphological and ISSR Molecular Markers
}

\author{
D.K. Janghel, Krishan Kumar, Mukesh Kumar, A.K. Chhabra
}

10.18805/LR-4293

\begin{abstract}
Background: Chickpea (Cicer arietinum L.), commonly known as gram or Bengal gram, is a self-pollinated diploid plant $(2 n=2 x=16)$ ranked third after common bean and field pea. Genetic diversity assessment is the fundamental of any breeding programme, conservation of genetic resources and as a general guide for the choice of parents in hybrid breeding. The present investigation aimed to study the genetic diversity among 45 elite chickpea genotypes using agro-morphological traits and ISSR molecular markers.

Methods: The experimental material comprised of 45 elite chickpea genotypes, grown in randomized block design (RBD) with three replications under natural field conditions at Research Farm of Pulses Section, CCSHAU, Hisar during Rabi2014-15. Genetic divergence was studied using 11 agro-morphological traits by Non-hierarchical Euclidean cluster analysis and 25 ISSR primers using UPGMA based method.

Result: Genetic divergence study based on agro-morphological traits and molecular markers showed ample amount of genetic variation among elite chickpea genotypes which were discussed and compared their diversity analysis as well. The present study confirmed the importance of agro-morphological traits and ISSR markers for detecting tremendous amount of genetic diversity in chickpea which may be used to select good parental material in chickpea breeding programmes for further improvement.

Key words: Chickpea, Genetic diversity, ISSR, Molecular markers, PIC, Polymorphism.
\end{abstract}

\section{INTRODUCTION}

Chickpea (Cicer arietinum L.), commonly known as gram or Bengal gram, is the third most important cool season food legume crop after common bean- Phaseolus vulgaris L. and field pea- Pisum sativum L. (Aggarwal et al., 2015). It is widely distributed pulse crop across the tropics, subtropics and temperate regions (Rasool, 2013), cultivated in more than 50 countries of Asian, European, Ethiopian, African and Australian regions (FAO, 2013). It is a self-pollinated diploid plant $(2 n=2 x=16)$ with an estimated haploid genome size of about 740 mega-bases (Varshney et al., 2013). Genetic diversity assessment is the fundamental of any breeding programme, conservation of genetic resources and as a general guide for the choice of parents in hybrid breeding. Crossing between genetically diverse parents will lead to substantial amount of heterotic response in $F_{1}$ hybrids and release broad spectrum of variability in segregating generations (Johnson et al., 2015). Modern plant breeding and agricultural cropping systems have narrowed the genetic bases of cultivated chickpea. Therefore, it is time to explore new sources of variation for the development of superior hybrids as well as biotic and abiotic stress tolerant varieties in chickpea breeding programmes.

Identification and characterization of chickpea cultivars based on agro-morphological and molecular markers are essential for their efficient utilization and conservation. For effective breeding strategy in chickpea, heritability and genetic advance are key parameters for agro-morphological diversity analysis. Till now, genetic variability studies in chickpea have been focused on important traits such as 1000 grain weight, number of branches, flowering time, pod
Department of Genetics and Plant Breeding, College of Agriculture, Chaudhary Charan Singh Haryana Agricultural University, Hisar125 004, Haryana, India.

Corresponding Author: D.K. Janghel, Department of Genetics and Plant Breeding, College of Agriculture, Chaudhary Charan Singh Haryana Agricultural University, Hisar-125 004, Haryana, India. Email: jangheld1515@hau.ac.in

How to cite this article: Janghel, D.K., Kumar, K., Kumar, M. and Chhabra, A.K. (2021). Genetic Diversity Assessment in Chickpea (Cicer arietinum L.) through Agro-morphological and ISSR Molecular Markers. Legume Research. 44(7): 751-758. DOI: 10.18805/LR-4293.

Submitted: 03-12-2019 Accepted: 30-04-2020 Online: 28-07-2020

size, pod number and harvest index (Wang et al., 2010). Genetic diversity measurement using molecular markers are most rapid, versatile, highly informative and reliable in characterization of complex traits such as yield, adaptation and disease resistance, which are not easily visible or measurable. Various molecular markers are available for evaluating genetic diversity in chickpea; RAPD (Random Amplified Polymorphic DNA) is one of the most commonly used markers (Sudupak et al., 2002), however, it detected only little diversity, less reproducible and influenced by variable factors, such as concentration of DNA, $\mathrm{MgCl}_{2}, \mathrm{Taq}$ polymerase and PCR cycles (Nkongolo et al., 2002). Intersimple sequence repeats (ISSR) are semi-arbitrary SSR primers complementary to a target microsatellite region at highly stringent condition in PCR, therefore, they are more reliable, consistent, highly polymorphic and reproducible than RAPD markers as well as it has been successfully used 
to study genetic diversity and phylogenetic relationships in chickpea (Aggarwal et al., 2011).

\section{MATERIALS AND METHODS}

The experimental material comprised of 45 elite genotypes of chickpea included both Desi and Kabuli types (Table 1) which were taken from chickpea germplasm maintained at Pulses Section, Department of Genetics and Plant Breeding, C.C.S. Haryana Agricultural University, Hisar. These genotypes were grown in randomized block design (RBD) with three replications under natural field conditions at Research Farm of Pulses Section, C.C.S. Haryana Agricultural University, Hisar during Rabi 2014-15. Agrometeorological data during research period of chickpea crop from Nov. 2014 to Apr. 2015 is presented in Fig 1.

For agro-morphological diversity analysis 11 quantitative traits viz., days to $50 \%$ flowering, days to maturity, number of secondary branches per plant, number of pods per plant, plant height $(\mathrm{cm})$, number of seeds per pod, 100 seed weight $(\mathrm{g})$, seed yield per plant $(\mathrm{g})$, standard germination (\%), seedling length $(\mathrm{cm})$ and seedling vigour index-I were used to assess the genetic variability, heritability, genetic advance and genetic divergence. Genotypic and phenotypic coefficients of variation (GCV and PCV) were estimated for each trait by using the formula suggested by Burton and Devane (1953); heritability and genetic advance by Hanson et al. (1956) and Johnson et al. (1955). Genetic divergence was studied using Nonhierarchical Euclidean cluster analysis (Spark, 1973) and dendrogram was constructed using similarity distance matrix by NTSYS-PC 2.02 software.

For molecular diversity analysis, genomic DNA was isolated from leaves of 3-4 weeks old seedlings using CTAB (Cetyl Trimethyl Ammonium Bromide) method as given by Saghai-Maroof et al. (1984) with slight modifications. The quality and quantity of DNA were estimated by UV spectroscopy and $0.8 \%$ agarose gel electrophoresis using a standard genomic $\lambda$ DNA $(50 \mathrm{ng} / \mu \mathrm{l})$. The genetic fingerprinting of 45 chickpea genotypes was performed using 25 di-nucleotide repeat motif ISSR primers viz., $(A G)_{8} T$, $(\mathrm{AG})_{8} \mathrm{C},(\mathrm{AG})_{8} \mathrm{G},(\mathrm{GA})_{8} \mathrm{~T},(\mathrm{GA})_{8} \mathrm{C},(\mathrm{GA})_{8} \mathrm{~A},(\mathrm{CT})_{8} \mathrm{G},(\mathrm{CA})_{8} \mathrm{~T}$, $(\mathrm{CA})_{8} \mathrm{~A},(\mathrm{GT})_{8} \mathrm{~A},(\mathrm{GT})_{8} \mathrm{C},(\mathrm{TC})_{8} \mathrm{~A},(\mathrm{TC})_{8} \mathrm{C},(\mathrm{TC})_{8} \mathrm{G},(\mathrm{AC})_{7} \mathrm{~T}$, $(A C)_{8} \mathrm{C},(\mathrm{AC})_{8} \mathrm{G},(\mathrm{TG})_{8} \mathrm{~A},(\mathrm{TG})_{8} \mathrm{C},(\mathrm{TG})_{8} \mathrm{G},(\mathrm{AG})_{8} \mathrm{AT},(\mathrm{AG})_{8} \mathrm{AC}$,
$(\mathrm{AG})_{8} \mathrm{TA}$ and $(\mathrm{GA})_{8} \mathrm{AT}$. PCR amplification was performed in applied biosystem thermocycler in $20 \mu \mathrm{l}$ reaction volume of mixtures containing $50 \mathrm{ng}$ template DNA, $100 \mu \mathrm{M}$ each dNTP, 10X PCR buffer, $1.5 \mathrm{mM} \mathrm{MgCl}, 0.6 \mu \mathrm{M}$ primers and 1.5 unit of Taq DNA polymerase. Amplified PCR products were resolved in $1.5 \%(\mathrm{w} / \mathrm{v})$ agarose gel electrophoresis at $5 \mathrm{~V} / \mathrm{cm}$ in $1 \mathrm{X}$ TBE buffer with staining dye ethidium bromide $(10 \mathrm{mg} / \mathrm{ml})$ and $1 \mathrm{~kb}$ DNA ladder. The $0 / 1$ binary matrix was calculated using similarity genetic distance Simqual subprogramme (Rohlf, 1990) and dendrogram was constructed using Unweighted Pair-Group Method with Arithmetic average (UPGMA) a sub-programme of NTSYS-PC software 2.02. The polymorphic information content (PIC) of a primer is calculated as:

Where,

$$
\mathrm{PIC}=1-\sum_{\mathrm{i}-1}^{\mathrm{n}} \mathrm{Pi}^{2}
$$

(Pi) Is the frequency of $i^{\text {th }}$ allele generated by ISSR primer. $(n)=$ Number of alleles.

\section{RESULTS AND DISCUSSION \\ Agro-morphological diversity analysis}

Days to $50 \%$ flowering, days to maturity, number of pods/ plant and seed yield/ plant ranged from 75.00 (ICCV-2) to 97.00 days (HC-3); 122.00 (ICCV-2) to 160.00 days (Gaurav); 31.67 (E-100Ym) to 84.33 (HK-1) and 7.37 (PG-5) to $23.40 \mathrm{~g}(\mathrm{HK}-1)$, respectively (Table 2$)$. The magnitude of PCV was higher than their corresponding GCV for all the traits which indicated the sensibility of traits to environmental factors. The estimates of GCV and PCV were observed high for 100 seed weight, number of pods/ plant, seed yield/ plant and number of secondary branches/ plant (Table 2). The estimates of heritability (broad sense) were found high for days to maturity, days to $50 \%$ flowering, 100 seed weight, seed yield/ plant and number of pods/ plant and moderate for number of secondary branches/ plant, seedling vigour index-I, seedling length, standard germination per cent and plant height (Table 2). Furthermore, genetic advance as per cent of mean (GAM) was observed high for number of pods/ plant, seed yield/ plant, 100 seed weight and moderate for number of secondary branches/ plant (Table 2). GCV together with high heritability and genetic advance were considered as effective means of genetic gain to be expected from phenotypic selection. Efficient selection indices and

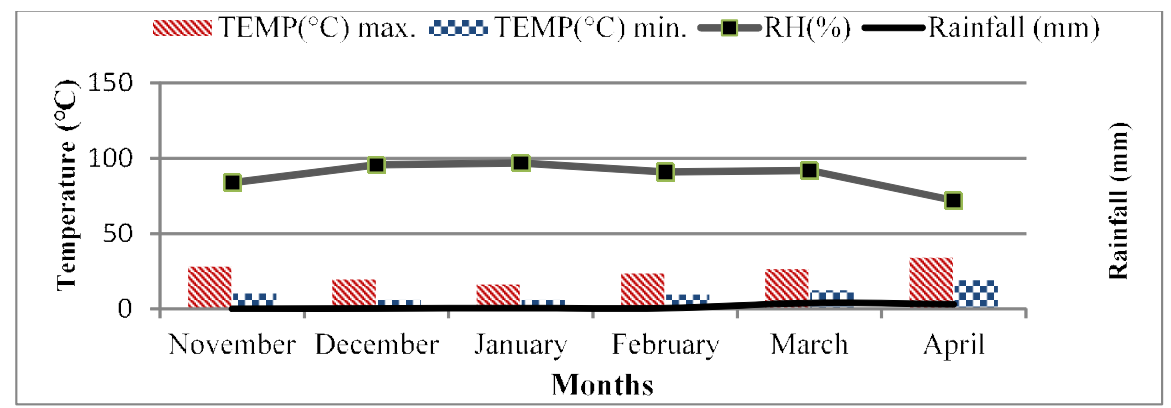

Fig 1: Agro-meteorological data during research period of chickpea crop.

(Source: Department of Agricultural Meteorology, C.C.S. Haryana Agriculture University, Hisar). 
Table 1: List of elite chickpea genotypes selected for genetic diversity analysis.

\begin{tabular}{|c|c|c|}
\hline Genotype & Pedigree & Source \\
\hline DCP 92-3 & Selection from local germplasm & IIPR, Kanpur \\
\hline GNG 1999 & GNG $1490 \times$ FG 703 & RAU, Sriganganagar \\
\hline Gaurav & C $235 \times E 100 Y$ & CCSHAU, Hisar \\
\hline H 208 & $(\mathrm{~S} 26 \times \mathrm{G} 24) \times \mathrm{C} 235$ & CCSHAU, Hisar \\
\hline HC 1 & $\mathrm{~F} 61 \times \mathrm{L} 550$ & CCSHAU, Hisar \\
\hline $\mathrm{HC} 3$ & $\mathrm{~L} 550 \times \mathrm{E} 100 \mathrm{Y}(\mathrm{m})$ & CCSHAU, Hisar \\
\hline HC 5 & $\mathrm{H} 89-78 \times \mathrm{H} 89-84$ & CCSHAU, Hisar \\
\hline Hima & Maintained at $\mathrm{CCSHAU}$, Hisar & CCSHAU, Hisar \\
\hline ICC 4958 & Selection from Jabalpur, Madhya Pradesh germplasm & ICRISAT, Hyderabad \\
\hline ICCV 6 & L $550 \times$ L 2 & IIPR, Kanpur \\
\hline ICCV 10 & PI $231 \times$ PI 265 & ICRISAT, Hyderabad \\
\hline JG 315 & Selection from Kanpur germplasm (WR 315) & JNKVV, Jabalpur \\
\hline Katila & Maintained at CCSHAU, Hisar & CCSHAU, Hisar \\
\hline NARC 9006 & Maintained at CCSHAU, Hisar & CCSHAU, Hisar \\
\hline PBG 5 & $B G 257 \times E 100 Y$ & PAU, Ludhiana \\
\hline PDG 4 & $(\mathrm{GL} 769 \times \mathrm{GF} 88421) \times \mathrm{GF} 8976$ & PAU, Ludhiana \\
\hline PDG 84-16 & Maintained at CCSHAU, Hisar & PAU, Ludhiana \\
\hline PG 517 & Maintained at CCSHAU, Hisar & MPKV, Rahuri \\
\hline RSG 888 & $\mathrm{RSG} 44 \times \mathrm{E} 100 \mathrm{Y}$ & RARI, Durgapura \\
\hline RSG 931 & RSG $44 \times$ RSG 524 & RARI, Durgapura \\
\hline WR 315 & Maintained at CCSHAU, Hisar & CCSHAU, Hisar \\
\hline DKG 876 & ICCV $88506 \times$ ICCV 96030 & CSK HPK, Dhaulakuan \\
\hline E $100 Y m$ & Mutant of E $100 Y$ & CCSHAU, Hisar \\
\hline H 00-256 & $\mathrm{HC}-1 \times$ C. reticulatum & CCSHAU, Hisar \\
\hline H 04-99 & H 99-242 × (H 92-68 × E 100Ym $)$ & CCSHAU, Hisar \\
\hline H 07-157 & H 86-143 × NARC 9006 & CCSHAU, Hisar \\
\hline H 08-18 & H 99-264 × H 00-256 & CCSHAU, Hisar \\
\hline H 09-96 & HC $5 \times$ ICCV 96029 & CCSHAU, Hisar \\
\hline H 10-57 & $(\mathrm{H} 99-264 \times \mathrm{ICC} 4958) \times \mathrm{H} \mathrm{00-256}$ & CCSHAU, Hisar \\
\hline Rajas & Phule G $91028 \times$ Bhima & MPKV, Rahuri \\
\hline Vishal & K $850 \times$ ICCL 80074 & MPKV, Rahuri \\
\hline GNG 2146 & PG 89-224 × GNG 1508 & RAU, Sriganganagar \\
\hline CSJ 741 & RSG $931 \times$ CSJD 901 & RARI, Durgapura \\
\hline BG 1053 & ICCV $3 \times$ FLIP $88-20$ & IARI, New Delhi \\
\hline GNG 1969 & IPCK 96-3 × GNG 1382 & RAU, Sriganganagar \\
\hline HK 1 & $\{\mathrm{~L} 550 \times \mathrm{E} 100 \mathrm{Y}(\mathrm{m})\} \times(\mathrm{ICCC} 32 \times \operatorname{ICC} 82001)$ & CCSHAU, Hisar \\
\hline HK 2 & $\{\mathrm{H} 82-2 \times \mathrm{E} 100 \mathrm{Y}(\mathrm{m})\} \times$ Bhima & CCSHAU, Hisar \\
\hline HK 4 & HK $92-94 \times$ HK 1 & CCSHAU, Hisar \\
\hline ICCV 2 & L $550 \times$ Gaumirchil & ICRISAT, Hyderabad \\
\hline JGK 1 & $($ ICCV $2 \times$ Surutato $) \times$ ICC 73-44 & JNKVV, Jabalpur \\
\hline JGK 27 & JGK $6 \times$ JGK 4 & JNKVV, Jabalpur \\
\hline L $550(K)$ & PB $7 \times$ Rabat & PAU, Ludhiana \\
\hline GNG 2237 & HK 98-155 × IPCK 402 & RAU, Sriganganagar \\
\hline HK 07-234 & ICCV $92325 \times$ ICCV 95423 & CCSHAU, Hisar \\
\hline IPCK 10-151 & ICC $\times 14 / 2647$ & IIPR, Kanpur \\
\hline
\end{tabular}

combination breeding would be more productive based on number of secondary branches, number of pods, 100 seed weight, seed yield and germination percentage for improvement in chickpea yield since these traits were shown high variability, heritability coupled with genetic advance in present investigation. Similar findings of genetic variations on these traits were reported by Nizama et al., 2013; Peerzada et al., 2014 and Mallu et al., 2015.

Genetic divergence study reveals the extent of genetic diversity and directs the plant breeders for selection of genotypes. Non-hierarchical Euclidean cluster analysis based on 11 agro-morphological traits grouped 45 elite 


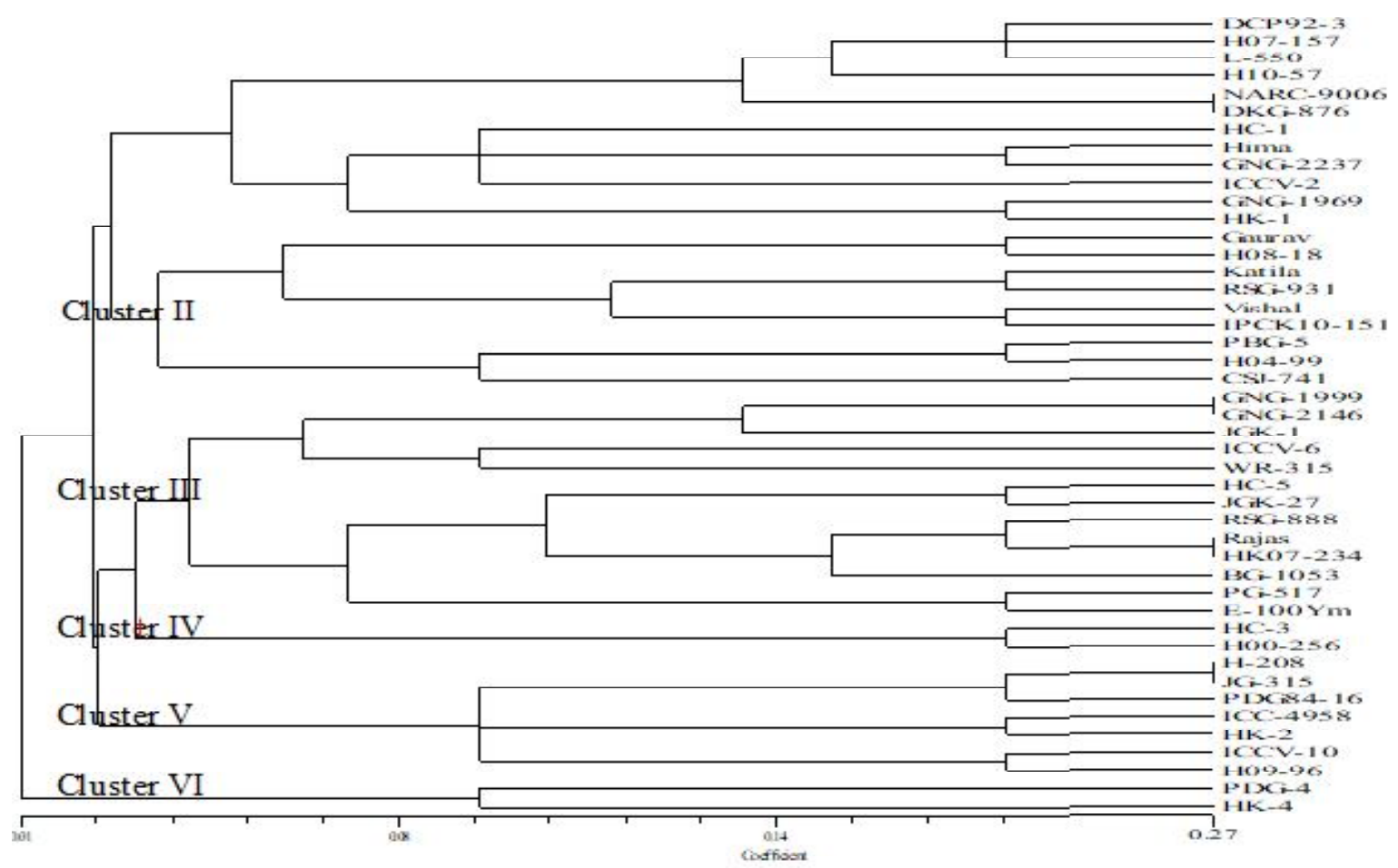

Fig 2: Dendrogram showing clustering pattern of 45 elite chickpea genotypes based on agro-morphological traits.

Table 2: Estimates of genetic variability for eleven quantitative traits among chickpea genotypes.

\begin{tabular}{|c|c|c|c|c|c|c|c|c|c|c|}
\hline \multirow{2}{*}{ Traits } & \multirow{2}{*}{ Mean } & \multicolumn{2}{|c|}{ Range } & \multicolumn{2}{|c|}{ Variance } & \multicolumn{2}{|c|}{$\mathrm{CV}$} & \multirow{2}{*}{$\begin{array}{l}\mathrm{H}_{\mathrm{bs}} \\
(\%)\end{array}$} & \multicolumn{2}{|c|}{ Genetic advance } \\
\hline & & Min. & Max. & Genotypic & Phenotypic & GCV & PCV & & Standard & Mean (\%) \\
\hline$\overline{\mathrm{DF}}$ & 88.43 & 75.00 & 97.00 & 19.16 & 21.07 & 4.95 & 5.19 & 90.96 & 8.60 & 9.73 \\
\hline DM & 142.87 & 122.00 & 160.00 & 61.04 & 63.67 & 5.47 & 5.59 & 95.86 & 15.76 & 11.03 \\
\hline NSBPP & 6.75 & 4.00 & 9.67 & 1.93 & 2.58 & 20.56 & 23.77 & 74.83 & 2.47 & 36.64 \\
\hline NPPP & 48.83 & 31.67 & 84.33 & 168.33 & 187.56 & 26.57 & 28.05 & 89.75 & 25.32 & 51.85 \\
\hline $\mathrm{PH}$ & 55.57 & 45.33 & 66.33 & 24.09 & 38.05 & 8.83 & 11.10 & 63.32 & 8.05 & 14.48 \\
\hline NSPP & 1.41 & 1.03 & 1.63 & 0.01 & 0.02 & 6.10 & 10.43 & 34.18 & 0.10 & 7.34 \\
\hline $100 \mathrm{SW}$ & 20.31 & 13.20 & 36.83 & 33.88 & 34.33 & 28.67 & 28.86 & 98.69 & 11.91 & 58.66 \\
\hline SYPP & 13.61 & 7.37 & 23.40 & 13.05 & 14.59 & 26.54 & 28.06 & 89.43 & 7.04 & 51.69 \\
\hline $\mathrm{G}(\%)$ & 82.02 & 78.00 & 86.67 & 6.35 & 9.97 & 3.07 & 3.85 & 63.68 & 4.14 & 5.05 \\
\hline$S L$ & 29.42 & 25.17 & 32.43 & 1.91 & 2.79 & 4.70 & 5.68 & 68.49 & 2.36 & 8.01 \\
\hline SVI & 2415.3 & 1997.3 & 2788.5 & 28722.0 & 38306.9 & 7.02 & 8.10 & 74.98 & 302.32 & 12.52 \\
\hline
\end{tabular}

$\mathrm{DF}=$ Days to $50 \%$ flowering, $\mathrm{DM}=$ Days to maturity, NSBPP $=$ Number of secondary branches $/$ plant, NPPP $=$ Number of pods $/ \mathrm{plant}, \mathrm{PH}=$ Plant height $(\mathrm{cm}), \mathrm{NSPP}=$ Number of seeds/ pod, $100 \mathrm{SW}=100$ seed weight $(\mathrm{g})$, SYPP $=$ Seed yield $/$ plant $(\mathrm{g})$, G $(\%)=\mathrm{Germination}(\%)$, $S L=$ Seedling length $(\mathrm{cm}), S V I=$ Seedling vigour index $-I, C V=$ Coefficient of variance, $G C V=$ Genotypic coefficient of variation, $P C V=$ Phenotypic coefficient of variation, $\mathrm{H}_{\mathrm{bs}}=$ Broad sense heritability.

genotypes of chickpea into six distinct clusters (Fig 2). Dendrogram (Fig 2) showed relatively high magnitude of resemblance among the genotypes of different clusters as well as revealed the most of chickpea genotypes were included into cluster I and III (12 and 13 genotypes, respectively) followed by cluster II (9 genotypes), cluster $\mathrm{V}$ (7 genotypes) and lowest number of genotypes in cluster IV and $\mathrm{VI}$ (each with two genotypes). In dendrogram, genotypes which are nearer to each other are more closely related than those placed away. Interestingly, the genotype DCP 92-3 was positioned extreme place from HK-2 indicated maximum genetic distance between them. Likewise, other chickpea genotypes showing positional distance between them in X-axis which indicating the genetic distance between these genotypes. So, the chickpea genotypes with maximum genetic diversity could be utilized in crossing programme as parents to develop superior hybrids with desirable combination of traits. The above findings are broadly in agreement with report of Sreelakshmi et al., 2010 and Ojha et al., 2011.

Some chickpea genotypes had been identified as promising for different agro-morphological traits (Table 3). 
For multiple cropping systems, genotypes with shorter duration are more prominent. The genotypes, HK-1, HC-3, ICCV-6, ICCV-10, C-235, H04-99, H07-157, H08 -18, JGK-1 and JGK-27 were found promising for most of the traits (Table 3). The gene pool can be established by diverse genotypes with traits of interest or by creating wide crosses. Thus, such diverse genotypes could be used as a base population for developing important breeding lines and population.

\section{Molecular diversity analysis}

Quantity and quality of DNA estimated by UV spectroscopy from genomic DNA of different chickpea genotypes were ranged from $300-1000 \mu \mathrm{g} / \mathrm{ml}$ and 1.78 to 1.88 (A260:A280 ratio) respectively, indicating that the DNA was free from contaminants like polyphenols, polysaccharides, proteins and RNAs. Further, $0.8 \%$ agarose gel electrophoresis showed the single band of high molecular weight, confirmed that genomic DNA was intact and free from any mechanical or enzymatic degradation. The number of amplified bands by ISSR primers (Fig 3 and 4) was varied from 3 to 10 (Table 4). A total of 146 bands were amplified across 45 chickpea genotypes revealing an average of 5.8 bands/ primer/ genotype (Table 4). The primer sequences (TC) ${ }_{8} A,(T C)_{8} G$ and $(\mathrm{GT})_{8} \mathrm{C}$, each produces least number of bands (3), whereas, $(A G)_{8} T$ and $(G A)_{8} A$ amplified maximum number of

Table 3: Promising chickpea genotypes for different agro-morphological traits.

\begin{tabular}{ll}
\hline Agro-morphological traits & Promising chickpea genotypes \\
\hline Early flowering $(<90$ days $)$ & ICCV-2, ICCV-6, ICCV-10 and JG-11 \\
Early maturity $(<130$ days) & Vikas, ICCV-2, ICCV-6, ICCV-10 and JG-11 \\
Higher secondary branches per plant $(>7$ branches/ plant) & H08-18, Gaurav, H-208, HC-1, HC-3, C-308, GNG-663 and GNG-2237 \\
Higher number of pods per plant $(>60$ pods/ plant) & HK-1, GNG-2237, HK-4 and GNG-1969 \\
Higher number of seeds per pod $(>1$ seeds/ pod) & C-235, CSG-8962, ICCV-6, ICCV-10 and DKG-876 \\
Seed yield per plant $(>20 \mathrm{~g} /$ plant) & HK-1, H08-18, HK-2, HK-4, HC-3, HC-5, H07-157 and GNG-2237 \\
Higher 100 seed weight $(>25 \mathrm{~g})$ & GNG-663, ICC-4958, JGK-1, JGK-27, Virat and IPCK2010-92 \\
Tall stature $(>60 \mathrm{~cm})$ & JGK-27, NARC-9006, PBG-5, JGK-1 and L-550 \\
Short stature $(<45 \mathrm{~cm})$ & Hima, BG-372, C-235 and GNG-2146 \\
Higher standard germination $(>85 \%)$ & Gaurav, HC-3, GNG-2237, C-235, H-208, HC-5, Hima, ICCV-6, ICCV- \\
& 10 and ICCV-2 \\
\hline
\end{tabular}

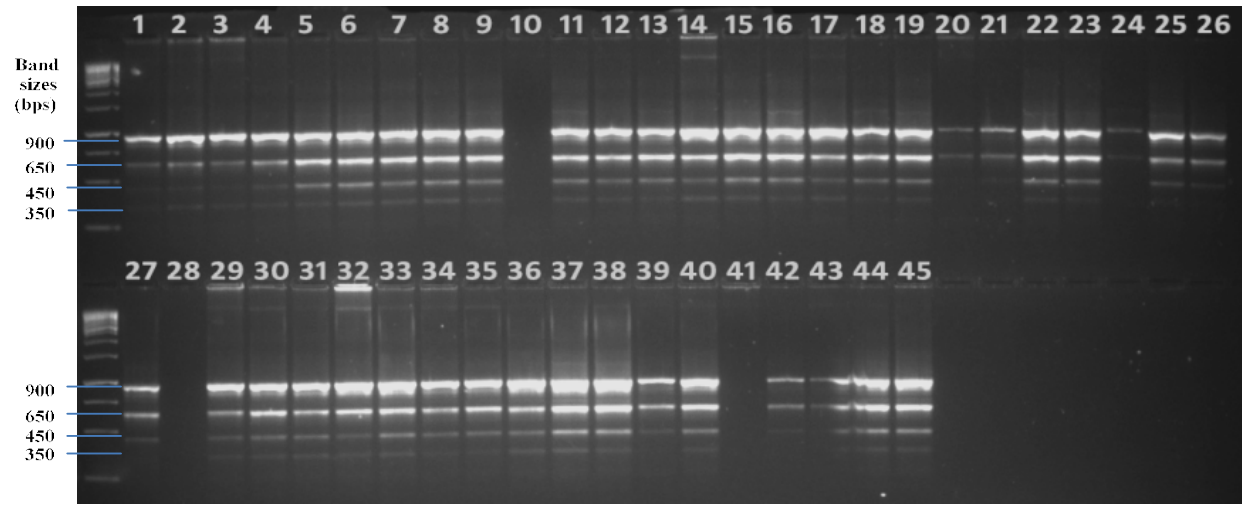

Fig 3: Polymorphism in 45 elite genotypes of chickpea using primer UBC-808 (1-45 chickpea genotypes).

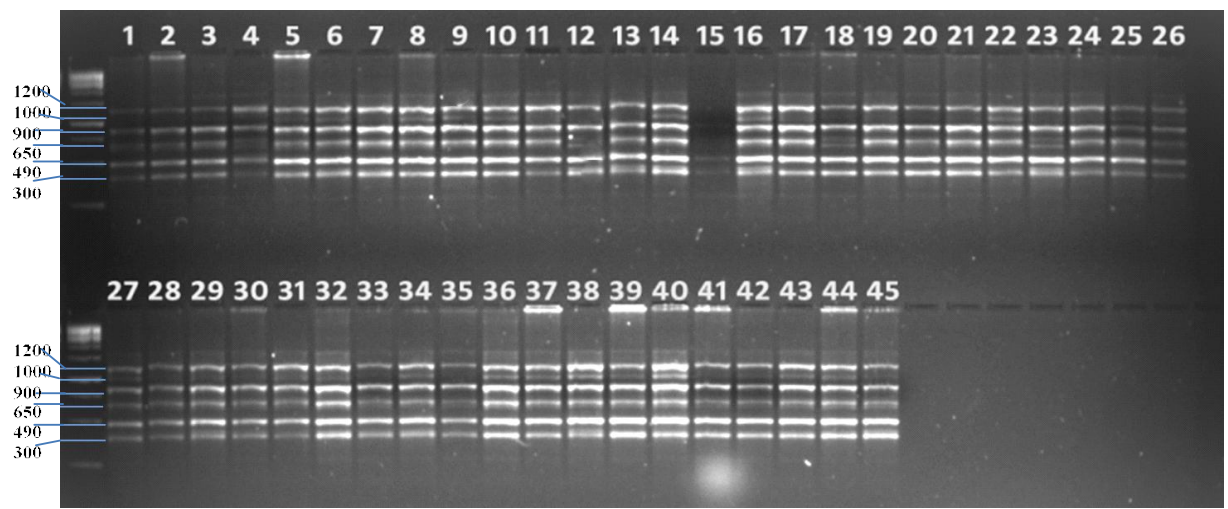

Fig 4: Polymorphism in 45 elite genotypes of chickpea using primer UBC-836 (1-45 chickpea genotypes). 
Genetic Diversity Assessment in Chickpea (Cicer arietinum L.) through Agro-morphological and ISSR Molecular Markers

Table 4: Evaluation of genetic diversity among chickpea genotypes using ISSR primers.

\begin{tabular}{|c|c|c|c|c|c|c|c|}
\hline Primers & Base sequences & Bases & $\begin{array}{l}\text { Range } \\
\text { (bp) }\end{array}$ & $\begin{array}{c}\text { Number of } \\
\text { amplified } \\
\text { bands }\end{array}$ & $\begin{array}{l}\text { Number of } \\
\text { polymorphic } \\
\text { bands }\end{array}$ & $\begin{array}{c}\text { Polymorphism } \\
\text { (\%) }\end{array}$ & $\begin{array}{c}\text { PIC } \\
\text { values }\end{array}$ \\
\hline UBC-807 & $(A G)_{8} T$ & 17 & $580-1000$ & 10 & 6 & 60.0 & 0.89 \\
\hline UBC-808 & $(A G)_{8} C$ & 17 & $400-1300$ & 7 & 5 & 71.4 & 0.83 \\
\hline UBC-809 & $(A G)_{8} G$ & 17 & $700-1200$ & 7 & 2 & 28.6 & 0.86 \\
\hline UBC-810 & $(\mathrm{GA})_{8} \mathrm{~T}$ & 17 & $650-1300$ & 8 & 5 & 62.5 & 0.87 \\
\hline UBC-811 & $(\mathrm{GA})_{8} \mathrm{C}$ & 17 & $520-1250$ & 7 & 4 & 57.1 & 0.86 \\
\hline UBC-812 & $(\mathrm{GA})_{8} \mathrm{~A}$ & 17 & $300-750$ & 10 & 4 & 40.0 & 0.90 \\
\hline UBC-815 & $(\mathrm{CT})_{8} \mathrm{G}$ & 17 & $600-1500$ & 4 & 3 & 75.0 & 0.75 \\
\hline UBC-816 & $(\mathrm{CA})_{8} \mathrm{~T}$ & 17 & $500-1300$ & 5 & 3 & 60.0 & 0.79 \\
\hline UBC-817 & $(\mathrm{CA})_{8} \mathrm{~A}$ & 17 & $300-1100$ & 6 & 4 & 66.7 & 0.83 \\
\hline UBC-818 & $(\mathrm{CA})_{8} \mathrm{G}$ & 17 & $270-1250$ & 7 & 3 & 42.9 & 0.86 \\
\hline UBC-819 & $(\mathrm{GT})_{8} \mathrm{~A}$ & 17 & $300-1400$ & 4 & 2 & 50.0 & 0.75 \\
\hline UBC-820 & $(\mathrm{GT})_{8} \mathrm{C}$ & 17 & $350-1300$ & 3 & 2 & 66.7 & 0.67 \\
\hline UBC-822 & $(\mathrm{TC})_{8} \mathrm{~A}$ & 17 & $500-1300$ & 3 & 1 & 33.3 & 0.67 \\
\hline UBC-823 & $(\mathrm{TC})_{8} \mathrm{C}$ & 17 & $580-1000$ & 8 & 3 & 37.5 & 0.87 \\
\hline UBC-824 & $(\mathrm{TC})_{8} \mathrm{G}$ & 17 & $400-1300$ & 3 & 1 & 33.3 & 0.66 \\
\hline UBC-825 & $(\mathrm{AC})_{7} \mathrm{~T}$ & 15 & $700-1200$ & 4 & 2 & 50.0 & 0.75 \\
\hline UBC-826 & $(A C)_{8} C$ & 17 & $650-1300$ & 6 & 2 & 33.3 & 0.83 \\
\hline UBC-827 & $(A C)_{8} G$ & 17 & $520-1250$ & 4 & 3 & 75.0 & 0.73 \\
\hline UBC-828 & $(\mathrm{TG})_{8} \mathrm{~A}$ & 17 & $300-750$ & 5 & 3 & 60.0 & 0.79 \\
\hline UBC-829 & $(\mathrm{TG})_{8} \mathrm{C}$ & 17 & $600-1500$ & 3 & 1 & 33.3 & 0.67 \\
\hline UBC-830 & $(T G)_{8} G$ & 17 & $500-1300$ & 5 & 4 & 80.0 & 0.80 \\
\hline UBC-834 & $(\mathrm{AG})_{8} \mathrm{AT}$ & 18 & $300-1100$ & 7 & 5 & 71.4 & 0.86 \\
\hline UBC-835 & $(\mathrm{AG})_{8} \mathrm{AC}$ & 18 & $270-1250$ & 7 & 3 & 42.9 & 0.86 \\
\hline UBC-836 & $(\mathrm{AG})_{8} \mathrm{TA}$ & 18 & $300-1400$ & 6 & 2 & 33.3 & 0.83 \\
\hline UBC-840 & $(\mathrm{GA})_{8} \mathrm{AT}$ & 18 & $350-1300$ & 7 & 3 & 42.9 & 0.86 \\
\hline Total & & - & - & 146 & 76 & 1307.1 & 20.03 \\
\hline Average & & - & - & 5.84 & 3.04 & 52.28 & 0.80 \\
\hline
\end{tabular}

bands (10). The number of polymorphic loci ranged from one (UBC-822; UBC-824 and UBC-829) to six (UBC-807 primers). The 3.04 out of amplified 5.84 ISSR alleles per locus were found to polymorphic. Overall $52.28 \%$ polymorphic loci among the di-nucleotide repeat motif primers and UBC-809 showed least polymorphism (28.6\%), whereas, highest by UBC-808 (71\%) and UBC-830 (80\%). PIC values ranged from 0.66 (UBC-824) to 0.90 (UBC-812) with an average of 0.80 . The ISSR primers viz., UBC-807, UBC-808, UBC-810, UBC-815, UBC-817, UBC-820, UBC827, UBC-828, UBC-830 and UBC-834 were shown significantly high polymorphism (\%) as well as PIC values which could be used for differentiation of chickpea germplasm for future breeding programme. Similarly, Singh et al., 2014 obtained polymorphism (\%) ranged from 50 to $100 \%$ across 12 chickpea genotypes and, Aggarwal et al., 2015 from 63.6 to $100 \%$ across 125 chickpea genotypes.

Cluster analysis based on UPGMA method divided all 45 chickpea genotypes into two major clusters and six subclusters (Fig 5), while, the Jaccard's similarity coefficient ranged from 0.16 to 0.97 . In the major cluster $A$, genotype (DCP 92-3) exists as an independent type. The major cluster
$B$, sub-divided into five sub-clusters. Clustering pattern in major cluster $B$ shown that the sub-cluster $V$ was largest consisting maximum number of 35 genotypes; in sub-cluster I only one genotype (JG-315) in separate existence, three in sub-cluster II (JGK-27, JGK-1, H 04-99), two in sub-cluster III (HK-1, ICC-4958) and three in sub-cluster IV (HK 07-234, H 07-157, HC-5). Similar results using ISSR markers based UPGMA clustering were reported by Singh et al., 2014; Aggarwal et al., 2015; Babayeva et al., 2018.

\section{Comparisons of diversity analysis based on agro- morphological and molecular markers}

Genetic divergence study based on 11 agro-morphological traits and 25 molecular markers (ISSR) by Non-hierarchical Euclidean and UPGMA based method, respectively, using NTSYS PC 2.02 software showed the ample amount of genetic variation among 45 elite genotypes of chickpea. However, the agro-morphological Euclidean clustering is different from molecular UPGMA based clustering. Dendrogram clearly depicted that clustered formed by agromorphological markers (six clustered) were more than the ISSR markers (only two major and six sub-clusters) which 
indicated the addition of more primers for efficiently discrimination of chickpea genotypes. Clustering pattern revealed that genotype DCP-92-3 was found in extreme places from both the Euclidean and UPGMA cluster analysis, respectively (Table 5) and genotype HK-4 was grouped in extreme down position of Euclidean cluster and sub-cluster $\mathrm{V}(\mathrm{A})$ of major cluster B (Table 5) as per the UPGMA cluster analysis which confirmed the clusters made by Euclidean method was in close proximity of molecular based UPGMA clustering. However, some genotypes differed in their clustering pattern for example $\mathrm{HC}-1$ and HC-3 genotypes were morphologically grouped in different clusters (cluster I and IV, respectively) based on Euclidean method, whereas, in the same cluster [mini-cluster (iv) of sub-cluster $V(A)$ of major cluster $B$ ] based on UPGMA method which indicated the effects of environmental factors in phenotypic expression of agro-morphological traits. Nevertheless, the genetic relationship observed using molecular markers may provide

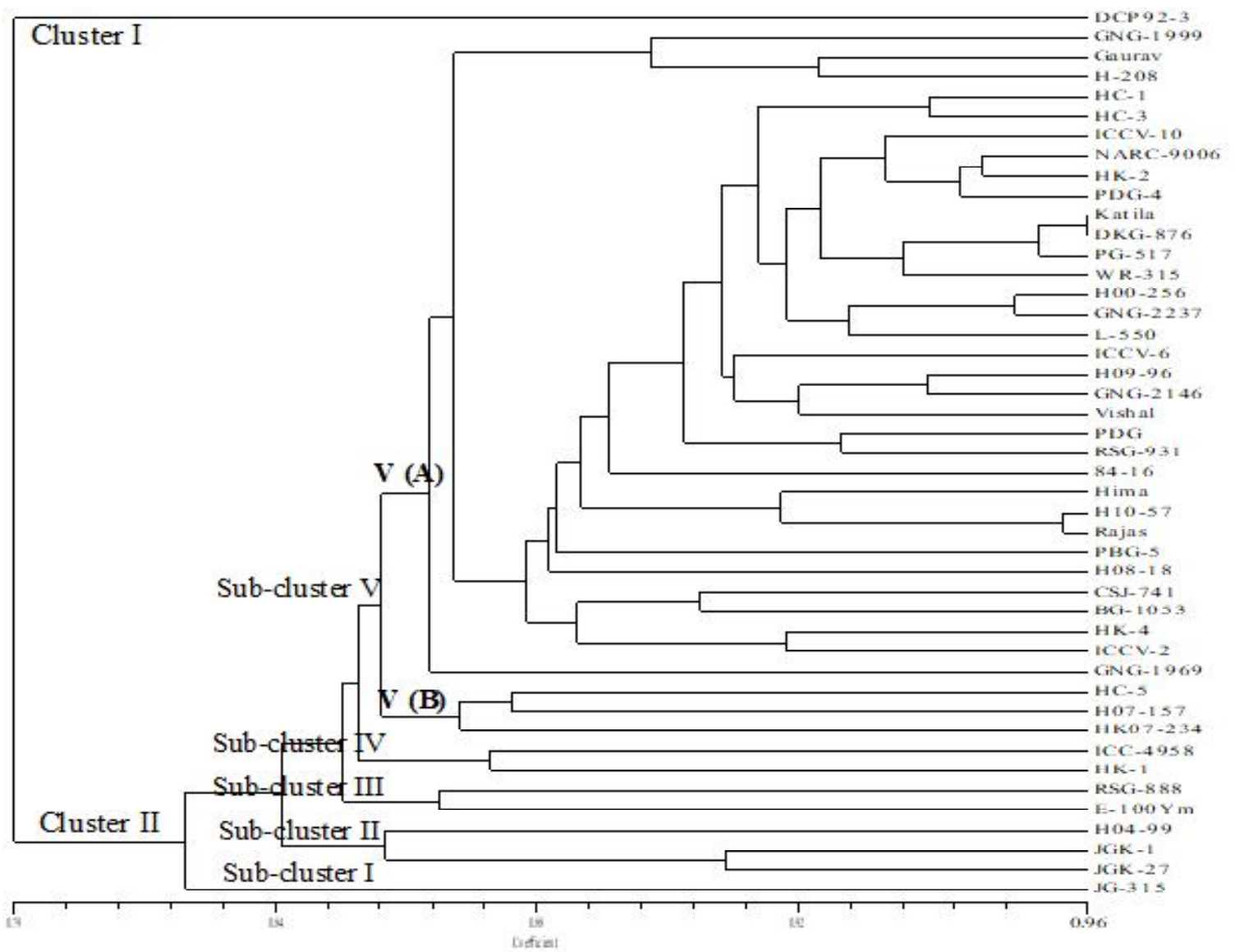

Fig 5: Dendrogram showing the clustering pattern of 45 elite chickpea genotypes based on 25 ISSR markers.

Table 5: Comparisons of diversity analysis based on agro-morphological and molecular markers.

\begin{tabular}{lll}
\hline Genotypes & Euclidean based clusters & UPGMA based clustering \\
\hline DCP-92-3 & Cluster I & Sub-cluster I of Major cluster A \\
JG-315 & Cluster IV & Sub-cluster I of Major cluster B \\
JGK-1, JGK-27 & Cluster III & Sub-cluster II of Major cluster B \\
HK 07-234, HC-5 & Cluster III & Sub-cluster IV of Major cluster B \\
IPCK 10-151, RSG-931 & Cluster II & Mini-cluster (i) of sub- cluster (V) B \\
GNG-1969 & Cluster I & Mini-cluster (ii) of Sub-cluster (V) B \\
H 10-57, Hima & Cluster I & Mini-cluster (iii) of Sub-cluster (V) B
\end{tabular}

H 04-99, HK-1, ICC-4958, H 07-157, WR-315, Rajas, ICCV-2, HK-4, BG-1053, CSJ-741, H 08-18, PBG-5, PG-517, L-550, GNG-2237, H 00-256, Vishal, PDG 84-16, PDG-4, NARC-9006, ICCV-6, DKG-876, RSG-888, E-100Ym, Katila, GNG-2146, H 09-96,

Distributed in all seven clusters from cluster I to VII
Distributed in all five sub-clusters of $(\mathrm{V}) \mathrm{B}$ of major cluster $\mathrm{B}$.

ICCV-10, HK-2, HC-3, HC-1. 
information on the history and biology of genotypes but does not necessarily reflect what may be observed with respect to agro-morphological traits.

\section{CONCLUSION}

The present study confirmed the importance of agromorphological traits and ISSR molecular markers for detecting tremendous amount of genetic diversity among chickpea genotypes. Highly variable agro-morphological traits viz., number of secondary branches, number of pods, 100 seed weight, seed yield and germination percentage and highly polymorphic proficient ISSR primers viz., UBC807, UBC-808, UBC-810, UBC-815, UBC-817, UBC-820, UBC-827, UBC-828, UBC-830 and UBC-834 which can discriminate the chickpea genotypes more efficiently, so these traits and primers could be effectively used for detecting genetic diversity in future chickpea breeding. The genotypes viz., H 04-99, H 07-157, H08 -18, HC-3, HC-5, HK-1, HK-2, ICCV-2, ICCV-6, ICCV-10, JG-11, DCP 92-3, JG-315, JGK-1 and JGK-27, showed high level of genetic diversity based on agro-morphological and molecular markers which may be used to select genetically diverse parents in chickpea breeding to carry out new crossing programmes successfully for further improvement in yield.

\section{REFERENCES}

Aggarwal, H., Rao, A., Rana, J.S., Singh, J., Kumar, A., Chhokar, V., Beniwal, V. (2015). Assessment of genetic diversity among 125 cultivars of chickpea (Cicer arietinum L.) of Indian origin using ISSR markers. Turkish Journal of Botany. 39: 218-226.

Aggarwal, H., Rao, A., Rana, J.S., Singh, J., Kumar, A., Chhokar, V., Beniwal, V. (2011). Inter-simple sequence repeats reveal significant genetic diversity among chickpea (Cicer arietinum L.) cultivars. Journal of Plant Science. 6: 202-212.

Babayeva, S.M., Nasibova, J.A., Akparov, Z.I., Shikhaliyeva, K.B., Mammadova, A.D., Izzatullayeva, V.I., Abbasov, M.A. (2018). Application of DNA markers in determination of fusarium resistance and genetic diversity in chickpea. Legume Research. 41(4): 537-542.

Burton, G. and Devane, E.M. (1953). Estimating heritability in tall festuca (Festuca arundinacea) from replicated clonal material. Agronomy Journals. 45: 478-481.

FAO (2013). FAOSTAT. Food and Agriculture Organization of the United Nations. http://faostat.fao.org/default.aspx.

Hanson, C.H., Robinson, H.F., Comstock, R.E. (1956). Biometrical studies in yield in segregating populations of Korean lespediza. Agronomy Journal. 48: 214-318.

Johnson, H.W., Robinson, H.F., Comstock, R.E. (1955). Estimates of genetic and environmental variability in soybean. Agronomy Journal. 47: 314-318.

Johnson, P.L., Sai, S., Nanda, H.C., Sharma, R.N. (2015). Variability and stability analysis for seed yield and its components in chickpea (Cicer arietinum L.). Journal of Food Science and Agricultural Technology. 1(1): 152-156.
Mallu, T.S., Mwangi, S.G., Nyende, A.B., Rao, N.V.P.R.G., Odeny, D.A., Rathore, A., Kumar, A. (2015). Assessment of genetic variation and heritability of agronomic traits in chickpea (Cicer arietinum L.). International Journal of Agronomy and Agricultural Research. 6(1): 77-88.

Nizama, J.R., Patel, S.R., Patel, A.I. (2013). Genetic variability and heritability among quantitative traits in chickpea under tropical region. Asian Resonance. 2(4): 45-48.

Nkongolo, K.K., Michael, P., Gratton, W.S. (2002). Cloning and characterization of RAPD markers inferring genetic relationships among pine species. Genome. 45: 51-58.

Ojha, V.S., Shiva, N., Singh, R. (2010). Genetic variability in chickpea (Cicer arietinum L.). Progressive Research. 5(2): 275-276.

Peerzada, O.H., Chaurasia, A.K., Ahmad, N.I. (2014). Evaluation of chickpea germplasm (Cicer arietinum L.) Desi for yield and yield contributing traits. An International Quarterly Journal of Life Sciences. 9(4): 1805-1809.

Rasool, S. (2013). Genetic diversity as revealed by RAPD analysis among chickpea genotypes. Pakistan Journal of Botany. 45(3): 829-834.

Rohlf, R.J. (1990). NTSYS-PC, Numerical Taxonomy and Multivariate Analysis System, Version 1.8. Exeter Software, Setauket, New York. http://www.exetersoftware.com/cat/ntsyspc/ ntsyspc.htm.

Saghai-Maroof, M.A., Solima, K.M., Jorgenson, R.A., Allard, R.W. (1984). Ribosomal DNA spacer-length polymorphisms in barley: Mendelian inheritance, chromosomal location and population dynamics. Proceedings of the Natural Academy of Sciences. USA, 81: 8014-8018.

Singh, P.K., Sharma, H., Srivastava, N., Bhagyawant, S.S. (2014). Analysis of genetic diversity among wild and cultivated chickpea genotypes employing ISSR and RAPD markers. American Journal of Plant Sciences. 5: 676-682.

Spark, D.N. (1973). Euclidean cluster analysis. Algorithm As. 58. Applied Statistics. 22: 126-130.

Sreelakshmi, C., Shivani, D., Kumar, C.V.S. (2010). Genetic divergence, variability and character association studies in Bengal gram (Cicer arietinum L.). Electronic Journal of Plant Breeding. 1(5): 1339-1343.

Sudupak, A., Akkaya, S., Kence, A. (2002). Analysis of genetic relationships among perennial and annual Cicer species growing in Turkey using RAPD markers. Theoretical and Applied Genetics. 105: 1220-1228.

Varshney, R.K., Song, C., Saxena, R.K., Azam, S., Yu, S., Sharpe, A.G., Cannon, S., Baek, J., Rosen, B.D., Tar'an B. (2013). Draft genome sequence of chickpea (Cicer arietinum) provides a resource for trait improvement. Nature Biotechnology. 31: 240-248.

Wang, N., Hatcher, D.W., Tyler, R.T., Toews, R., Gawalko, E.J. (2010). Effect of cooking on the Composition of beans (Phaseolus vulgaris L.) and chickpea (Cicer arietinum L.). Food Research International. 43: 589-594. 